\title{
Living arrangements and intergenerational monetary transfers of older Chinese
}

\author{
TAICHANG CHEN*, GEORGE W. LEESON $\dagger$ and \\ CHANGPING LIU‡
}

\begin{abstract}
Previous studies show a decline in parent-child co-residence among the elderly. This study examined the effect of living away from adult children on upward intergenerational monetary transfers by analysing a 2006 survey of 19,947 persons aged 6o and above and selected from 20 provinces in China. Results indicate that elderly who were not co-residing but had at least one adult child living in another community/village within the city/county were likely to receive more intergenerational monetary transfers than those who were living with children. Living close to children, rather than co-residing with them, might be the primary living arrangement for older Chinese people in the foreseeable future. The findings have important programme and policy implications for countries such as China, which has the largest elderly population in the world. There is a strong need for the development of specific public care support systems focused on the elderly population, in general, and elderly in rural areas, in particular.
\end{abstract}

KEY WORDS - living arrangements, intergenerational monetary transfers, older adults, China.

\section{Introduction}

Living arrangements are vital to intergenerational monetary transfers and welfare in old age, particularly in developing countries, which lack social security systems that provide universal coverage. This is because the household plays a key role in providing social support and interactions, and determines the social role of older people (Waite and Hughes 1999). In China, living arrangements for older people carry a special meaning. Within the Confucian paradigm, filial piety (xiao) regulates the relationship

* School of Public Administration and Policy, Renmin University of China, Beijing, China.

$\uparrow$ Oxford Institute of Population Ageing, University of Oxford, UK.

\$ Center for Social Security Studies, Wuhan University, China. 
between children and their elders, requiring not only that children fulfil the duties relating to taking care of parents, but also doing so with the proper attitude (Ikels 2004). Under the influence of Confucianism, older Chinese traditionally co-reside with one or more of their married children; usually the oldest son. The family-based support mechanism by which the young cared for the old was through shared living arrangements. For the full span of its 2000-year history, the Chinese family has functioned as a close-knit social unit from which, ideally, older persons would draw instrumental, emotional and financial support (Wu and Schimmele 2008).

Demographic transitions, however, have raised concerns about the reliability and sustainability of the family unit as providing the bedrock of old-age support. On the one hand, rapid ageing is taking place as a result of a drastic decline in both fertility and mortality and is reshaping the population age structure in China. Data from the latest two censuses show that the proportion of people aged 6o or over grew from 10 per cent in 2000 to 13.3 per cent in 2010 (National Bureau of Statistics of China 2012). On the other hand, the younger generation, especially rural residents of working age, have moved into cities (or to other cities) in large numbers as the result of income inequality between regions and the policies that have stimulated labour mobility. These trends have reduced household size, generated changes in living arrangements and increased the prevalence of 'empty nest families' (families in which older persons live alone and do not co-reside with adult children) in both urban and rural areas.

While formal old-age support is underdeveloped, intergenerational monetary transfers still account for a significant proportion of parental incomes in China. Despite the efforts on reforming its pension system, a recent study (Zheng and Lu 2011) estimated that only about half of retirees receive any form of pension, and about half of workers are covered by the current pension system in China. This is particularly the case for elderly in rural areas, where formal old-age insurance was first established in $2010 .{ }^{1}$ In addition, the latest population census shows that about $4^{1}$ per cent of Chinese elderly rely on family members (primarily adult children) as their primary source of income, with a higher proportion for rural elderly than that of urban elderly (Table 1). It is important for China, which has the largest elderly population in the world, to understand the impacts of living arrangement on intergenerational monetary transfers.

\section{Living arrangements and intergenerational monetary transfers in China}

Social scientists have long been analysing the relationship between environment and individuals' behaviours (House 1977), particularly such 
T A B LE 1. Composition of primary source of income of Chinese elderly in $2 O I O$

\begin{tabular}{lcccr}
\hline & All & Cities & Townships & Counties \\
\hline & & \multicolumn{3}{c}{ Percentages } \\
Pension & 24.12 & 66.30 & 26.29 & 4.06 \\
Family members & 40.72 & 22.43 & 44.52 & 47.74 \\
Work income & 29.07 & 6.61 & 22.27 & 41.18 \\
Other & 6.09 & 4.66 & 6.92 & 6.48 \\
Total & 100 & 100 & 100 & 100 \\
& & & & \\
\hline
\end{tabular}

Source. Author's calculation from the 2010 Population Census (National Bureau of Statistics of China 2012).

relationships among older adults (Lawton 1977). The geographic proximity between parents and their adult children is an important part of the 'opportunity structure for interaction' (Bengtson and Roberts 1991) which has strong implications for family relations and influence on intergenerational monetary transfers. A general theoretical proposition is that out-migration results in diminished informal support resources among the elderly parents who remain behind. Technological progress and compulsory education laws create outside options which allow children to leave the extended family and the parental home. Parents living separately might lose control over their children's labour income. This is because parental control over their adult children's labour income is much easier to exercise in a setting where multiple generations live together in the same household, compared to a setting where young couples live away from their parents (Folbre 1994). The modernisation theory also points to a relationship between urbanisation with industrialisation and decreased old-age support, partly as a result of the increased geographical distance between family members, and partly because of a decline in family orientation (Aboderin 2004; Goode 1963).

It is generally agreed that older persons' living arrangements are determined by both preferences and constraints. Previous studies in developed countries have explained the increasing prevalence of independent living among the aged is the result of rising demand for 'privacy' which accompanied post-Second World War income growth (e.g. Beresford and Rivlin 1966; Boyd 1991; Michael, Fuchs and Sharon 1980). Constraints, particularly economic considerations, dictate living arrangements in old age because they affect the ability of the elderly to afford to live independently (Boyd 1991). In fact, despite their preference to live independently, the inability to pay the costs of housing and living expenses may prevent older persons from doing so. 
Recent empirical evidence demonstrated that parent-child co-residence had declined over time in China (Meng and Luo 2008). The authors explained that this trend in urban areas is the result of housing reforms implemented during the 199os that have increased housing availability, and in so doing have enabled older persons who preferred to live alone to do so. Palmer and Deng (2008) ascribed the decline in co-residence to the income growth of older parents. Research by Zeng and Wang (2003), using macro census data of 1982, 1990 and 2000, demonstrated a similar trend of living arrangements for older people, and attributed it to significant changing norms, declining fertility and increasing population mobility.

It is not yet clear how intergenerational transfer is affected by this trend of parents' living away from children. On the one hand, if family ties are indeed weakening as a result of the prevalence of non-co-residence with adult children, then the traditional family-based transfer mechanisms may be ill-suited to supporting older parents. On the other hand, changes in living arrangements need not signal an end to adult children's responsibility for their older parents. Intergenerational monetary transfers, including money and in-kind transfers, can take place across as well as within households. The question is whether such inter-household transfer mechanisms fully substitute for the traditional intra-household transfers.

While the literature has been concerned mainly with the determinants of co-residence (e.g. Korinek, Zimmer and Gu 2011 ; Zimmer 2005) and its positive impacts on older people's psychological wellbeing (e.g. Silverstein, Cong and $\mathrm{Li}$ 2006), previous studies investigating correlation between living arrangements and intergenerational monetary transfers have not reached a consensus, mainly because different data-sets were applied. Benjamin, Brandt and Rozelle (2000) used household level data in Hebei and Liaoning provinces, and found that older people who did not live in an extended household were slightly financially worse off than those who coresided with children. Another study (Sun 2002), based on a 1994 survey in Baoding city, claimed that the probability of receiving monetary support was not affected by parents' living away from children. A similar result has been proposed by Zimmer and Kwong (2003), who attributed the insignificant impact of living arrangements upon monetary transfers to the fact that supporting a parent financially did not require living near him or her. More recently, Lei et al. (2011), by using the CHARLS survey collected in Zhejiang and Gansu provinces, found that compared with those who lived in other counties, adult children who lived in the same county as their parents were less likely to provide monetary transfers.

To develop and broaden these earlier studies, the paper presented here examines the association between living arrangements and the probability that an older adult in China would receive intergenerational monetary 
transfers from children as well as the amount involved. To this end, this study adopts quantitative methodology by exploring nationally representative survey data; it is likely to be the first study to analyse the impact of living arrangements on intergenerational monetary transfers using nationally representative survey data in China. Instead of the binary variable whether co-residing or not - used in previous analyses, this study introduces a trichotomous variable (whether living in the same household, living in the same city or living in the same province) to measure potential effects of children's living distance from their parents on intergenerational monetary transfers.

It is generally acknowledged by scholars that the uneven urban-rural development model has generated a vast gap in income level, living standards, educational systems, social insurance and public health services between urban and rural areas, which has created a China of 'two different nations' (Dixon 1981; Frazier 2010; Knight, Song and Jia 1999; Wang 2006). Although the Chinese government introduced the 'New Socialist Countryside' campaign ( 2005 to present) to address such rural-urban imbalance, it is fair to argue that China's cities were culturally, socially and economically more advanced and dynamic than its rural areas. The family practices of old-age support are supposed to be more traditional in rural areas than in urban areas, as predicted by the modernisation theory for family change (Goode 1963). Furthermore, due to the income gap and the uneven coverage of the pension system, intergenerational transfer is a more important source of old-age support in rural areas than that in urban areas, which may have significant impacts on the transfer patterns. For these reasons, rural elderly parents may benefit economically more from living away from children than their urban counterparts do. To explore the urban-rural differences, we presented our multivariate analyses with particular reference to urban and rural China. Specifically, this study addressed the following research questions:

- Research question 1: Are older parents with greater financial needs or greater instrumental needs more likely to co-reside with their children?

- Research question 2: Does living away from children have a negative effect on the receipt of intergenerational monetary transfers?

- Research question 3: Assuming that intergenerational monetary transfers occur, would living away from children have a negative effect on the size of transfers?

- Research question 4: Are families in rural areas engaged in more traditional familial practices (e.g. more likely to co-reside with children or more likely to receive monetary transfers from children) than those in urban areas? 
- Research question 5: Does living away from children have more significant impacts on monetary transfers for elderly in rural areas than for those living in urban areas?

\section{Methods}

\section{Sample selection}

The data for this study were derived from the Follow-up Sampling Survey of the Aged Population in Urban/Rural China (FUSSAPUR), a nationwide study of people aged 6o and older conducted by the China Research Center on Aging in June 2006. ${ }^{2}$ Interviews, guided by structured and urban-rural stratified questionnaires with validated measurement properties, were conducted face-to-face by trained interviewers from the local Committee on Ageing at the neighbourhood or village level. The FUSSAPUR survey assessed Chinese older persons in terms of family relations, income, physical health status and psychological wellbeing. Unless otherwise specified, monetary resource flows in this study are indicated in Chinese Yuan.

The FUSSAPUR samples were identified using a five-stage stratified method. First, 20 provincial-level administrative divisions were drawn from six macro-regions: North China, North-East China, East China, SouthCentral China, South-West China and North-West China. The number of provinces selected in each region is based on the demographic distribution of people aged 60 and older using statistics from the 2000 census. Within each region, provinces were randomly selected using Probability Proportional to Size Cluster Sampling. Second, eight city/county-level units (four urban cities and four rural counties) were selected in each province. ${ }^{3}$ Third, in each city/county, four neighbourhoods (shequ), which comprised one or more resident committees (juweihui) in urban areas, and four counties (xiangzhen), which comprised several village committees (cunweihui) in rural areas, were drawn. Fourth, $5^{\mathrm{O}}$ resident committees and $5^{\mathrm{o}}$ village committees were drawn in 16 neighbourhoods and 16 counties, respectively, in each province. Finally, a list of all households with at least one person aged 6o or older was provided by each resident committee or village committee. In the fifth-stage sampling process, ten households were drawn randomly from each resident committee and village committee, respectively. If there was more than one person aged 60 or older in a household, an eligible sample was randomly selected from the associated Kish Table.

The overall sample of FUSSAPUR consisted of 19,947 respondents, comprising 10,016 from urban areas and 9,931 from rural areas. The overall response rate was 97 per cent. Given that living arrangements across generations were the primary interest of this study, respondents with no 
children, or, for whom information about children was missing, were excluded. Consequently, 19,327 respondents (9,804 urban and 9,523 rural) were included in this study. Besides FUSSAPUR, the Sampling Survey of the Aged Population in Urban/Rural China (SSAPUR) conducted in 2000 using the same sampling method was applied in this study to demonstrate possible time trends over the period 2000-2006.

\section{Dependent variables}

In the interview, respondents were asked whether they had received money or in-kind transfers from and/or had given transfers to their children. They were also asked about the corresponding amount transferred, if applicable. Following previous studies (e.g. Cai, Giles and Meng 20o6; Lee and Xiao 1998; Lei et al. 2012), intergenerational monetary transfers were measured in two ways: (a) whether the parent received a positive net transfer from adult children (received a larger amount of money than the parent had given); and (b) the amount of net transfers to parents. The net transfer was calculated as the amount given to children subtracted from the amount received from children. Moreover, if the amount respondents gave their children was the same as, or larger than, the amount they received, we regarded the net amount received as zero and coded the incidence of receiving intergenerational monetary transfers as zero. Thus, this study discusses exchanges that involved older persons and all their adult children together, rather than exchanges between each parent-child pair presented in some previous studies (e.g. Lei et al. 2012).

The questionnaire asked respondents whether they had any children, and if so, how many surviving children they had, and where these children were living (this household, another village/neighbourhood in this city/county and another city/county). Using this information, we created a set of dummy variables for each distance to the closest living adult child, with the reference group as (a) 'living in the same household with at least one child'. The rest of the living arrangement dummy variables indicated the following issues: (b) non-co-residing, but with at least one adult child living in another community/village within the city/county; and (c) having all children living in another city/county or further. 4 For convenience, we subsequently used the terms 'co-residing', 'living nearby' and 'living far away' to describe each of the above three scenarios of parents' living arrangements.

\section{Control variables}

Socio-demographic and health variables known to influence wellbeing in later life were controlled in the regressions. These included age, gender, 
marital status, education, total number of children, health and need for financial support. Age and education attainment were measured in years, while gender was dummy coded as 1 (male) or o (female). Older adults' pre-transfer income was the sum of money they received from all sources except children's transfers and was included to control for economic adequacy. It consisted of pensions and other public assistance, income from work (which includes wages, salaries, and profits from farming and other own-account businesses), and property income such as rent and interest. The survey classified marital status into four categories: married, divorced (including separated), widowed or single (i.e. never married). Previous studies have shown that widowhood is associated both with living arrangements (e.g. Whyte 1997) and private transfers (e.g. Frankenberg, Lillard and Willis 2002). A dummy variable indicating whether an individual was widowed $(=1)$ or not $(=0)$ was included in this study to proxy the care needs of the older parents. We measured health by the activities of daily living (ADL)/instrumental activities of daily living (IADL) difficulty score. The ADL difficulty score was based on six tasks on which respondents were asked to report their degree of difficulty in performing: eating, dressing, toileting, bathing, getting on to and off a bed, and walking indoors. The IADL tasks referred to the following seven items: cooking meals, washing clothes, lifting 10 kilograms, sweeping the floor, grocery shopping, walking $1.5^{-2}$ kilometres, and walking up and down a flight of stairs. Each task was coded as follows: 1 (no difficulty), 2 (some difficulty) or 3 (unable to perform). The $\mathrm{ADL} / \mathrm{IADL}$ difficulty score was calculated as the sum of 13 scores divided by 13 , with a higher score indicating more functional limitations and hence a greater demand on instrumental supports. A dummy variable indicating whether the respondent or his/her spouse owned a property was included to control for wealth effect. Finally, the surveys asked respondents whether they would like to live with their children ('yes', 'indifferent' and 'no'), from which we created a variable to indicate older adults' willingness to co-reside with children ( 1 if reported 'yes'; o if reported 'indifferent' or 'no').

\section{Descriptive statistics}

The characteristics of the respondents are presented in Table 2, with selected characteristics from SSAPUR reported in parentheses. In general, co-residence was still prevalent in China during the period studied; about half the respondents were living with their adult children (urban $43.7 \%$, rural $54 \%$ ). The mean age of the respondents in rural areas was higher than that of their urban counterparts ( $71.4^{1}$ versus 70.97 years). There were more males than females in rural areas, while the proportion of 
T A B L 2. Means and ranges of analytic variables by urban/rural areas

\begin{tabular}{|c|c|c|c|c|c|}
\hline \multirow[b]{2}{*}{ Characteristics } & \multicolumn{2}{|c|}{ Urban areas } & \multicolumn{2}{|c|}{ Rural areas } & \multirow[b]{2}{*}{ Range } \\
\hline & Mean & SD & Mean & SD & \\
\hline Age & $70.97(68.65)$ & $6.76(6.6 \mathrm{o})$ & $71.4^{1}(69.5)$ & $7.217(6.86)$ & $60-103$ \\
\hline Men & $0.493\left(0.5^{10}\right)$ & $0.5^{\circ 0}(0.499)$ & $0.544(0.543)$ & $0.49^{8}\left(0.49^{8}\right)$ & o (no), 1 (yes) \\
\hline Widowed & $0.291(0.303)$ & $0.454(0.460)$ & $0.387\left(0.4^{11}\right)$ & $0.487(0.492)$ & o (no), 1 (yes) \\
\hline Years of schooling & $6.08(5.29)$ & $4.77(4.92)$ & $2.397(1.922)$ & $3.027(2.84)$ & $0-25$ \\
\hline Number of children & $3.27(3.66)$ & $1.44\left(1.5^{6}\right)$ & $4.094\left(4 \cdot 4^{6}\right)$ & $1.677(1.79)$ & $1-13$ \\
\hline Pre-transfer incomes ${ }^{1}$ & $10,578.33$ & $10,55^{0.86}$ & $1,989 \cdot 77$ & $4,041.79$ & $-20,000-196,000$ \\
\hline Received net transfers & $0.32(0.35)$ & $0.4^{6}\left(0.5^{0}\right)$ & $0.60(0.62)$ & $0.49(0.49)$ & o (no), 1 (yes) \\
\hline Amount of transfers received ${ }^{1}$ & $1,93^{1}\left(1,5^{\circ} 4\right)$ & $3,965(2,829)$ & $85^{1}(687)$ & $3,767(1,269)$ & $10-24,000$ \\
\hline Difficulties in ADL/IADL & 1.22 & 0.39 & 1.29 & $0.4^{1}$ & $1-3$ \\
\hline Owned property & $0.74(0.63)$ & $0.44(0.48)$ & $0.57(0.40)$ & $0.49(0.49)$ & o (no), 1 (yes) \\
\hline Willing to live with children & $0.37(0.44)$ & $0.4^{8}\left(0.5^{0}\right)$ & $0.55(0.66)$ & $0.5^{0}\left(0.4^{8}\right)$ & o (no), 1 (yes) \\
\hline \multicolumn{6}{|l|}{ Living arrangements: } \\
\hline Co-residing & $0.44\left(0.5^{2}\right)$ & $0.5^{0}\left(0.5^{0}\right)$ & $0.54(0.61)$ & $0.5^{0}\left(0.5^{0}\right)$ & o (no), 1 (yes) \\
\hline Living nearby & 0.54 & $0.5^{\circ}$ & 0.43 & $0.5^{\mathrm{O}}$ & o (no), 1 (yes) \\
\hline Living far away & 0.03 & 0.16 & 0.03 & 0.17 & o (no), 1 (yes) \\
\hline $\mathrm{N}$ & \multicolumn{2}{|c|}{$9,804(10,046)$} & \multicolumn{2}{|c|}{$9,5^{23}\left(9,85^{8}\right)$} & \\
\hline
\end{tabular}

Notes: Statistics of the Sampling Survey of the Aged Population in Urban/Rural China (SSAPUR) are reported in parentheses. The distribution of provinces is not reported but is available from the author on request. 1. Measured in Chinese Yuan. SD: standard deviation. ADL: activities of daily living. IADL: instrumental activities of daily living.

Source: The 2006 Follow-up Sampling Survey of the Aged Population in Urban/Rural China and 200o SSAPUR. 
females was slightly higher than that of males in urban areas. More rural samples presented with disadvantaged marital status (widowed) than urban samples $(38.7 \%$ versus $29 \%)$. On average, older parents in rural areas had more surviving children than urban parents had (4.o9 versus 3.07 children). The proportion of respondents who received net transfers were 60.2 and 32.2 per cent in rural and urban areas, respectively. By contrast, urban older persons were better educated and had a much higher pretransfer income5 (about five times more) than rural older persons, indicating that the former were more financially independent than the latter. In those instances in which net transfers had taken place, urban residents received a much larger amount than rural residents $(1,931.04$ versus $85^{\text {o. }} 44$ Yuan). Urban older persons were physically healthier than rural older persons, as reflected by a lower ADL/IADL difficulty score. More urban elderly owned property $(74.6 \%)$ than their rural counterparts $(56.4 \%)$. Finally, the statistics show that the samples were evenly distributed, about 5 per cent, in each province (not reported).

Compared with statistics from SSAPUR in 2000 (those in parentheses in Table 2), older Chinese both in urban and rural areas experienced the same time trend over the period from 200o to 2006: an increase in lifespan, more education, a greater amount of net transfer received and a higher proportion of older people owning property; and a decline in the number of children, the ratio of older adults receiving net transfers from children, the willingness to co-reside with children and the actual co-residence rate.

\section{Results}

Age patterns of living arrangements

We next demonstrated the age patterns of living arrangements, measured by the distance to the closest living adult child (Figure 1). The results indicate a U-shape relationship between the age of older parents and the proportion coresiding with children, and an inverted $U$-shape relationship between the age of older parents and the proportion of those whose closest child lived in the same city/county. For example, 48.85 and 53.44 per cent of respondents aged $60-64$ co-resided with children in urban and rural areas, respectively, while the proportions decreased to 40.75 and 52.14 per cent for those aged $7 \mathrm{O}^{-} 74$ and grew to 49.25 and 61.35 per cent for the oldest old (aged $8 \mathrm{o}+)$. Conversely, the proportion of respondents not living with children but who had at least one child living in the same city/county increased from $47.7^{6}$ and 41.31 per cent for those aged $60-64$ to $5^{6.93}$ and 45.31 per cent for those aged $7 \mathrm{O}^{-} 74$ in urban and rural areas, respectively. The ratios began decreasing and reached 48.98 and 37.17 per cent for the 


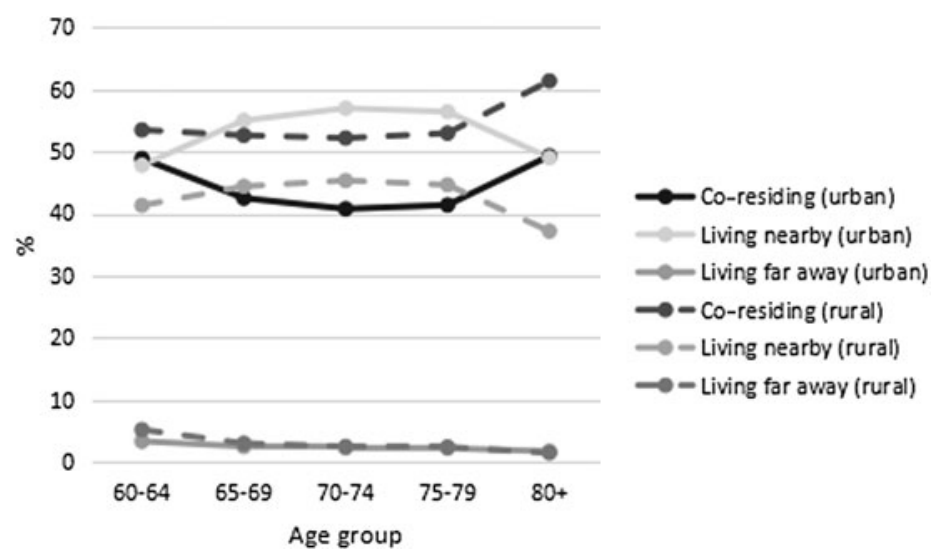

Figure 1. Multiple living arrangements of older adults by urban/rural areas.

Source The 2006 Follow-up Sampling Survey of the Aged Population in Urban/Rural China.

oldest old in urban and rural areas, respectively. Such age patterns were very clear for urban older persons (solid lines in Figure 1), but less so for those in rural areas (dashed lines in Figure 1). This is likely to be due to the fact that rural couples in the sample surveyed, and also more generally, had more children. In rural areas, even if one or some children moved out of the parental household, there was still a higher probability of having a child remaining in the same household than was the case in the urban context.

The survey asked respondents whether they owned the properties in which they are currently living. If we consider the property owners as the household head, this information offers clues as to distinguishing between adult children living in their parents' home versus adult children who have their parents living in the adult children's home. Figure 2 shows that among those who co-resided with children, urban elderly were more likely to have their children living in the parental home rather than living in their children's home for their rural counterpart for all age groups. Furthermore, the proportion of elderly living in their children's home increased with age, while the proportion of elderly who had their children living in the parental home decreased with age. This may be because younger cohorts and urban parents are more resourceful than their counterparts, i.e. with higher income and owning properties, which have enabled them to live independently.

\section{Determinants of multiple living arrangements}

To examine the determinants of multiple choices on older persons' living arrangements, multinomial logistic regression analysis was applied. The 


\section{Urban areas}

- Parents owned $=$ Children owned $\square$ Rented



\section{Rural areas}

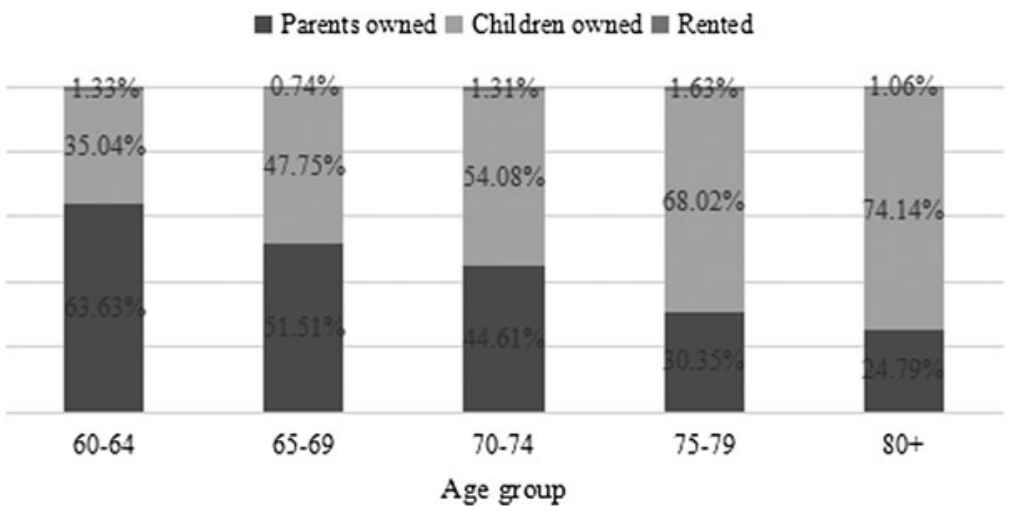

Figure 2. Ownership of the property which respondents were living in by urban/rural areas.

Source. The 2006 Follow-up Sampling Survey of the Aged Population in Urban/Rural China.

dependent variable in this section is the trichotomous variable of living arrangements mentioned previously (co-residing; living close to children; living far from children). Co-residing was set as the reference category in the multinomial logistic regressions; that is, the coefficient estimates indicate the impacts of the explanatory variables associated with the respective living arrangements relative to co-residing. Separate models controlling for the same covariates were calibrated for the urban and rural sub-samples, and Table 3 presents the results. The pseudo- $R^{2}$ values are 0.179 and 0.201 for urban and rural sub-samples, respectively, indicating reasonably good fit.

We first describe associations for individuals in urban areas. Age was associated with a higher likelihood of living close to children versus co-residing 
T A B L E 3. Multinomial logistic regressions on living arrangements of older adults

\begin{tabular}{|c|c|c|c|c|}
\hline & \multicolumn{2}{|c|}{ Urban areas } & \multicolumn{2}{|c|}{ Rural areas } \\
\hline & Live nearby & Live far away & Live nearby & Live far away \\
\hline Age & $0.31^{* * *}(0.06)$ & $0.18(0.16)$ & $0.22^{* * *}(0.06)$ & $0.18(0.16)$ \\
\hline Age-squared & $-0.00 * * *(0.00)$ & $-0.00(0.00)$ & $-0.001 * * *(0.00)$ & $-0.00(0.00)$ \\
\hline Male & $-0.10^{* *}(0.05)$ & $-0.15(0.15)$ & $-0.05(0.06)$ & $-0.21(0.15)$ \\
\hline Widowed & $-0.49 * * *(0.06)$ & $-0.29(0.18)$ & $-0.48 * * *(0.06)$ & $-0.3^{8 * *}(0.16)$ \\
\hline $\begin{array}{c}\text { Number of } \\
\text { children }\end{array}$ & $-0.03 *(0.02)$ & $-0.54^{* * *}(0.06)$ & $-0.07 * * *(0.02)$ & $-0.17^{* * *}(0.04)$ \\
\hline $\begin{array}{l}\text { Years of } \\
\text { schooling }\end{array}$ & $0.01 *(0.01)$ & $0.04^{* * *}(0.02)$ & $0.03^{* * *}(0.01)$ & $0.10^{* * * *}(0.02)$ \\
\hline $\begin{array}{l}\text { Difficulties in } \\
\text { ADL/IADL }\end{array}$ & $-0.22^{* * *}(0.07)$ & $-0.60 * *(0.25)$ & $-0.28 * * *(0.07)$ & $-0.02(0.20)$ \\
\hline $\begin{array}{l}\text { Pre-transfer } \\
\text { incomes }\end{array}$ & $0.00(0.00)$ & $0.00(0.00)$ & $0.01(0.01)$ & $0.00(0.01)$ \\
\hline $\begin{array}{l}\text { Owned } \\
\text { property }\end{array}$ & $0.03(0.06)$ & $0.22(0.18)$ & $0.40^{* * *}(0.05)$ & $0.75^{* * *}(0.15)$ \\
\hline $\begin{array}{l}\text { Willing to co- } \\
\text { reside }\end{array}$ & $-2.03^{* * *}(0.05)$ & $-1.22^{* * *}(0.15)$ & $-1.73^{* * *}(0.05)$ & $-1.08 * * *(0.13)$ \\
\hline Provinces & Yes & Yes & Yes & Yes \\
\hline Pseudo- $R^{2}$ & \multicolumn{2}{|c|}{0.179} & \multicolumn{2}{|c|}{0.201} \\
\hline $\mathrm{N}$ & \multicolumn{2}{|c|}{9,739} & \multicolumn{2}{|c|}{$9,4^{89}$} \\
\hline
\end{tabular}

Notes: The dependent variable is the multiple living arrangements. Co-residence is used as the reference category and the parameters of the co-residence equation are normalised to zero. Provincial dummies are included but not reported. Standard errors are reported in parentheses. 1. Measured in Chinese Yuan. ADL: activities of daily living. IADL: instrumental activities of daily living.

Significance levels: $* p<0.1, * * p<0.05, * * * p<0.01$.

with children. Moreover, the effect of age-squared was significant and negative. This is consistent with the finding of an inverted U-shape correlation of age and the proportion of older persons not co-residing but living close to children from Figure 1. Being male and widowed had negative effects on living close to, but had no effect on living far from children. Older parents with larger numbers of children, more functional limitations and who desired co-residence were less likely to live close to or to live far from children. Moreover, being willing to co-reside had a more negative effect on living close to children than on living far from children. As the reference category is co-residence, this also implies that older parents with such characteristics (male, widowhood, larger number of children, increased functional limitations and desiring coresidence) were more likely to co-reside with children.

It appears, for older parents in rural areas, that associations with sociodemographic characteristics were similar to those for urban residents. In particular, difficulties in ADL/IADL had a negative effect on living close to children but had no significant effect on living far from children. As 
for their urban counterparts, pre-transfer income had no significant effect on living arrangements. This absence of income effect on co-residence is not inconsistent with previous studies. For example, Jensen (2003) found that in South Africa parents' co-residence decision was not systematically related to their pension income. Analyses from Cai, Giles and Meng (2006) did not find a statistically significant relationship between pension income and probability of co-residence in urban China. Lei et al. (2011) also failed to find a statistically significant correlation between parental incomes and co-residence in China. Such unresponsiveness of co-residence to pre-transfer income may reflect the fact that the decision to co-reside might not be driven by the low income level of parents. The results provide an affirmative response to research question 1: older adults with greater instrumental needs were more likely to live with their children.

\section{Determinants of intergenerational monetary transfers}

A binary logistic model and an ordinary least square (OLS) regression were used to examine the effect of living arrangements on the incidence and the amount of net transfers, respectively. ${ }^{6}$ The current OLS regression assumes that zero net transfer represents a true value, when in fact it may reflect errors in reporting due to the omission of forms of labour, rent paying and other in-kind contributions. Therefore, we analyse the amount of net transfers separately as a robustness check using Tobit specifications which takes care of the left censoring of the independent variable at o Yuan.7 Because the distribution of net transfers was highly skewed, we used the natural logarithm of the net amount as the dependent variable in the OLS and Tobit regressions, in which case the coefficients are scale free and can be roughly interpreted as the effects in percentages. The key control variables - living arrangements - were defined as a set of dummy variables for each distance to the closest living adult child. The omitted living arrangement is 'co-residing'. The rest of the living arrangement dummy variables indicate the following issues: living nearby (yes $=1$, no $=0$ ); living far away (yes $=1$, no $=0$ ). Older parents' pre-transfer incomes as well as the same socio-economic and demographic characteristics that appeared in previous analyses were controlled for. Table 4 presents the results, with separate models for urban and rural sub-samples, respectively.

Taking first the urban elderly, results indicate that older adults living close to rather than co-residing with children (the reference group) were more likely to receive net transfers. Moreover, for those who received net transfers, living close to and far from children increased the amount of net transfers by 15 per cent $\left(=\mathrm{e}^{0.14}-1\right)$ and 68 per cent $\left(=\mathrm{e}^{0.5^{2}}-1\right)$, respectively (column 2). However, living far from children did not have a 


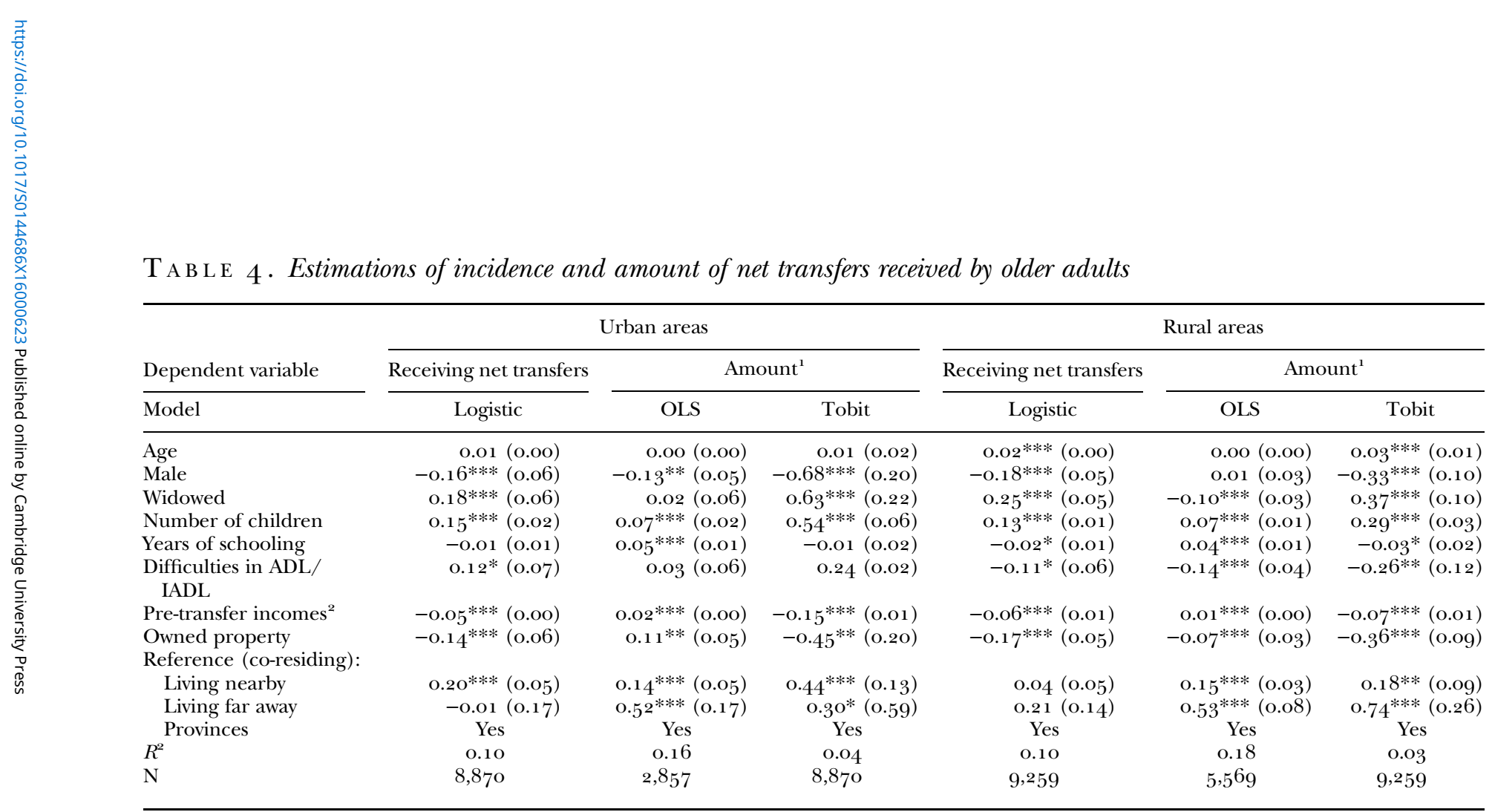

Notes: Provincial dummies are included but not reported. Standard errors are reported in parentheses. 1. Measured in Chinese Yuan and logged in the ordinary least square (OLS) regressions. 2. Measured in 1,00o Chinese Yuan. ADL: activities of daily living. IADL: instrumental activities of daily living. Significance levels: $* p<0.1, * * p<0.05, * * * p<0.01$. 
significant effect on the likelihood of receiving net transfers. Such insignificance may be the result of the small number of samples in this category.

Apart from urban older adults' living arrangements, some of their characteristics were also significant in affecting the incidence and the amount of net transfers received. It was found that respondents with the following characteristics were more likely to receive net transfers from children: if they were female, widowed and had more difficulty undertaking daily activities than if they were male, in a different marital status group and healthier; being female also increased the amount received. These findings imply children's transfers were need-based and are consistent with the altruism hypothesis (Becker 1974) that children are concerned with the welfare of their older parents and will transfer more if parents are needier.

As expected, having a larger number of surviving children meant a higher likelihood of receiving net transfers from them, and of receiving a larger amount. Education was also positively associated with the amount of the transfers that parents received. This may be because parents' and children's education are expected to be highly correlated, and children of better-educated parents may have earned more than children of less-educated parents. Elderly respondents' pre-transfer incomes and ownership of property showed a negative relationship with the incidence of receiving but a positive relationship with the amount received. The income and wealth effects observed would suggest exchange motivation between generations. Children are less likely to transfer if parents are better off. However, once such transfers occurred, children would transfer a larger amount to wealthier parents in order to assure a generous inheritance.

Turning to the results for the rural elderly, the following characteristics had effects on the incidence and the amount of net transfers received that were similar to those for their urban counterparts: number of children, education and pre-transfer income. Estimates of widowhood and difficulties in $\mathrm{ADL} / \mathrm{IADL}$ indicate that parents' instrumental needs were negatively associated with children's transfers. This may be because rural areas provide very limited formal old-age support, children tended to move to co-reside with parents to provide care rather than money when parents were in instrumental need, which is consistent with findings from Table 3. The significant negative correlation between property ownership and the incidence and amount of transfers received suggests a stronger need-based transfer motive in rural areas than in urban areas. The key variable, living arrangements, did not have significant effects on the incidence of transfers received. In cases where transfer did occur, older parents who lived close to and older parents who lived far from children received 16 and 69 per cent more, respectively, than those who co-resided with their children (Table 4 , column 5 ).

In columns 3 and 6 of Table 4 , we present results using Tobit estimates for the amount of net transfers as robustness checks for older parents in urban 
and rural areas, respectively. Coefficients on these models also suggest positive effects of living close to and living far from children on the amount of net transfers parents received. Yet, it is important to be mindful of the unrealistic assumptions regarding the error term in the Tobit model.

\section{Discussion}

Adult children have traditionally been seen as the main providers of old-age support for their older parents in many Asian countries, including China. Such support has been shown to be facilitated by a system of co-residence with children and parents, which allows for the close proximity necessary to provide assistance with a variety of tasks. However, socio-economic and demographic transition has been reshaping family structure and created concerns that changes in living arrangements might be undermining traditional support mechanisms for older adults. Other recent studies have taken up this question, some of which were cautiously optimistic that support traditions would survive and that elders would remain secure and supported. For example, recent works (e.g. Yan, Chen and Yang 2003; Zimmer 2005) looking at support from both co-resident and non-co-resident children for parents in China and elsewhere in Asia suggested living arrangement patterns consistent with a 'modified extended family' in which care and support of elders are maintained, although increasingly by children living at a distance.

By exploring the FUSSAPUR, this study depicted a broad picture of the living arrangements of Chinese older adults. The data demonstrate that older Chinese people have experienced a decline in co-residence with children over the period from 2000 to 2006. Nevertheless, the descriptive statistics do not show evidence that this kind of decline in co-residence has left older people isolated over time. On the one hand, co-residence was still prevalent in China during the period studied. Nearly half of older parents still lived with their children, with a higher proportion for rural elderly than urban elderly, with a very low proportion of elderly living far from children. On the other hand, as an elderly adult became older, he or she was less likely to live with children but more likely to have a child living nearby. Once an older parent reached the age of $70-74$, the older he or she was, it was more likely that he or she would co-reside with children, but was less likely to have a child living nearby.

This age pattern of living arrangements outlined above is likely to occur for two main reasons. First, both from the children's and the parent's point of view, non-co-residence is becoming prevalent. As scholars (Logan, Bian and Bian 1998) have pointed out, the decline in the decision to co-reside 
on the part of young elders reflected the normal process of maturation and increasing independence of the adult child. Moreover, living in the same city with older parents is a supplement of co-residence. Despite the fact that many adult children may have moved away, or may be in the process of moving out of their parental household, they still want to live close to their parents (e.g. in the same city/county) in order to be able to offer care. On the other hand, when older parents become frail and are not able to take care of themselves, their children move into the parents' household again to offer assistance, or these parents move to their children's households to seek assistance.

In the first part of the multivariate analysis, we investigated the determinants of older adults' living arrangements. The results suggest that those who wanted to co-reside, were less educated and had a greater number of children or instrumental needs were more likely to live with their children. Older parents who were less willing to co-reside were predicted to be more likely to live close to, rather than far from, children. The time trend statistics showed that, over the period 200o-2006, Chinese older adults experienced the following changes: an increase in education; and a decline in functional limitations, the average number of children, willingness to co-reside and in the actual coresidence ratio. If this time trend continues in the foreseeable future (which is quite likely to be the case), it would be reasonable to predict that there will be increasing numbers of older Chinese who do not co-reside with their children. Instead, older people are more likely to choose to live close to their children, in which case instrumental support can be still be maintained when needed.

The second part of multivariate analysis involved correlating the living arrangements and the incidence and the amount of net transfers received. In contrast to previous studies (e.g. Benjamin, Brandt and Rozelle 20oo; Lei et al. 2011 ), we did not find evidence that living arrangements had a negative impact on intergenerational monetary transfers from adult children to older parents. In particular, comparing with urban elderly who lived with children, those who lived close to children were more likely to do so, and to receive a larger amount of net transfers from children. Moreover, urban residents living far from children were predicted to receive a larger amount of net transfers than their co-resident counterparts. Although living arrangements had similar positive impacts on the amount of transfer received, they had no significant effects on the incidence of monetary transfers in rural areas.

With regards to urban-rural differences, our statistics suggest that family practices were more traditional in rural China than in urban areas: elderly parents in rural areas were more likely to co-reside with children and more likely to receive monetary transfers from children than their urban counterparts. However, the mechanism which facilitates co-residence and intergenerational monetary transfers for elders did not differ significantly across 
urban and rural households. This implies that the difference in family practices was driven by the differences in characteristics determining co-residence and intergenerational monetary transfers. For example, older people in rural areas had more children and were less resourceful (reflected by lower educational and income level) than their urban counterparts.

We did not find evidence that older parents in rural families reaped more rewards of living away from children than their urban counterparts did. This could be because children from rural families are generally less educated and less capable of contributing economically to old-age support, though they might be more willing to do so. It could also be because we did not take into account children's gender composition, which has important implications for the economic impact of geographic separation. In the traditional Chinese family system, sons are permanent members of their natal families and are expected to contribute to the economic wellbeing of their parents. Conversely, daughters are only transitory members of their natal families; after marriage, they begin to join their husband's extended family and to contribute to the family households of their parents-in-law. In this tradition, daughters generally cannot claim property from their parents and also have no formal obligation to support them (Whyte and $\mathrm{Xu} 2003$ ). In practice, on the one hand, empirical evidence in urban China did not support the traditional system that sons provide more monetary transfers to parents than daughters did (Lei 2013; Xie and Zhu 2009). This may be because cultural and socio-economic changes have eroded the traditional norms about sons' and daughters' roles in parental support. On the other hand, significant gender differences in financial support (with sons providing more) have been found in rural China (Lei 2013), where daughters' migration status had no significant impact on their financial transfers to parents (Cong and Silverstein 2011). This is because moving away from their natal villages is more the result of out-marriage than of labour market migration for women. Yet, for sons, moving away from their parents' households is more the result of labour-force migration to more distant locations offering better-paid jobs that enable them to contribute money in the form of remittances. Without information on gender composition, our estimated correlation between geographic separation and intergenerational monetary transfers from children may be biased. This would be particularly true in rural areas, where parents would stand to benefit economically from having distant sons but not distant daughters.

What implications does non-co-residence have for the overall wellbeing of older adults in China? Although our results suggest that living away from children generally increases the economic wellbeing of older parents, having distant children is likely to constrain parents with regard to receiving help with daily activities. Indeed, previous studies (Guo, Aranda and Silverstein 
2009) have shown that in rural Anhui province, elderly parents with migrant children received more financial support but less instrumental support than those who had all their children living nearby. Other studies (Sun 2002) have found evidence of responsibility sharing among siblings dependent on geographic distance from their parents, so that while those closer to parents tend to help with daily tasks, those living farther tend to provide financial transfers. These money transfers can be regarded as the distant children's compensation to their parents for their absence and inability to provide direct personal care. This may then be the case in our sample.

Confucian filial piety, which generally involves the provision of monetary support and care to parents, certainly remains an important practice in contemporary China, both urban and rural. However, the content and extent of the practice may have changed. With greater geographic dispersion, we suggest that filial piety may have, at least partially, become 'monetised'. In preliminary analyses, we found that an index designed to ascertain parents' evaluation of children's filial piety (that their children were 'very unfilial', 'unfilial' 'so so' and 'very filial') was weakly correlated with children's monetary transfers (with a significant estimated correlation coefficient of 0.12 ; not reported). We further conducted a one-way analysis of variance, which reveals that the mean values of children's monetary transfers in these five filial piety evaluation groups are statistically different (not reported). We are not able to demonstrate any causal relationships by using cross-sectional data because reversed causality may exist: filial children may provide more monetary transfers to parents. Nevertheless, our data provide some evidence that, from the parents' perspective, children's filial piety is positively correlated with the intergenerational monetary transfers they provided.

Although the traditional filial obligation requires a married child, usually a married son, to stay with his or her parents, rich children may be able to buy their way out of this obligation by providing cash, whereas poor children provide instrumental support to parents and also save money by living together. Distant children could choose to fulfil their filial practice by transferring more money to their parents rather than visiting them frequently. This trend is receiving positive support from the political sphere as well: China has tried to transform filial piety into legal obligations. The Law of the People's Republic of China on Protection of the Rights and Interests of the Elderly stipulates that children should provide their older parents with financial, instrumental and emotional support. Moreover, the government encourages people, especially those who live in rural areas, to sign a 'family support agreement' stipulating the types and amount of support children agree to provide for their parents (Xu 2001).

If we are correct in interpreting the extra monetary transfers from distant children as the result of monetised filial piety, it is not difficult to predict 


\section{Taichang Chen et al.}

that trends in non-co-residence in China will make a difference with respect to the future provision of support to older adults. Such changes in living arrangements coupled with the reduced number of children will make it more difficult for families to provide services to the elderly. Instead of financial support, the greater concern for old-age support in the future would be the provision of daily services since this requires frequent contact and even the constant presence of care-givers in the household. The ideal solution is to have both distant and local children, in which case monetary and instrumental supports are accessible. However, in light of the population control policy and socio-economic transformation, one may expect more elders to be living with fewer children in the future. Therefore, the elder-care sector must be developed to substitute for the supporting roles traditionally assumed by individual families. Both public and private providers are increasingly expected to play a more important role in providing affordable support to meet the different needs of future older Chinese people. If children's monetary transfers could be converted into daily care services through local elder-care institutions, then the family support mechanism would continue to function well.

Several limitations to our investigation deserve mention. First, very little information is available about the adult children and siblings of respondents. Key variables, such as the age of children and siblings, education, income, employment status, marital status and gender, are missing. As the family network is a potential provider of support in old age, such unobservables may bias analyses of the determinants of living arrangements and those of intergenerational monetary transfers. Second, intergenerational monetary transfers may suffer from measurement errors, particularly for co-resident households. For example, in the case of adult children living in the parental household, implicit transfers include either children buying food or paying utility bills or parents offering free accommodation, but these were unobservable. In this study we discussed transfers between older parents and all their children, instead of transfers between each parent-child pair. For this reason we believe implicit transfers between parents and co-resident children is likely to account for only a relatively small proportion of total transfers between parents and all children. Third, reversed causality generated by endogeneity is a potential threat to the validity of the conclusions in predicting transfer receipt. The evidence that living away from children is associated with increased monetary transfers needs to be interpreted with caution. It is also possible that older people receiving more monetary transfers were more likely to live independently as higher income reduces the constraints on doing so. The data did not enable us to evaluate competing explanations, but nevertheless it is clear that older parents living away from children enjoyed more monetary support from their children. 
In addition, the income resources of older people in rural areas were not clearly classified. As Lee and Xiao (1998) pointed out, inter-household transfers in rural China often take the form of labour input into family farming rather than giving money directly to the parents. The FUSSAPUR shows that for those who owned land in rural areas, two-thirds had their adult children's help in cultivating (authors' tabulations, not shown). However, the survey does not allow us to separate in-kind assistance on the part of children from parent's income. The possibility remains that children help their older parents with farming during busy farming seasons, in which case part of the income from farming should be counted as in-kind transfers. This may explain the insignificant impact of living arrangements on the incidence of transfers for rural elderly, because living distance to children may have little influence on the decision to provide indirect transfers to parents through cultivating parental lands. We hope this investigation has set the stage for future longitudinal and multigenerational designs that are better able to account for these potential biases.

To summarise, the results suggest that living close to children, rather than co-residing with them, is likely to be an important way of providing old-age support and is likely to persist in China for the foreseeable future as a result of the socio-economic and demographic transition. However, such changes in living arrangements do not necessarily weaken the family-based financial support mechanism or constrain intergenerational monetary transfers. Therefore, there is a strong need for interventions to ensure instrumental old-age support and for a policy to meet the care needs of the elderly, especially for those in rural areas, who are not living with adult children.

\section{Acknowledgements}

We are especially grateful to Andreas Hoff and Albert Park for their valuable advice. We should also like to thank Sarah Harper, Kenneth Howse, Maria Porter, Qianhan Lin and two anonymous reviewers for helpful comments and suggestions. All errors are ours. An early version of this work was presented at the XVIII ISA World Congress of Sociology in Yokohama, Japan, in July 2014. This work was supported by the Fundamental Research Funds for the Central Universities, and the Research Funds of Renmin University of China (grant number 13 XNFoog).

\section{NOTES}

1 For more details of China's pension system, see Chen (2014).

2 For more detailed descriptions of the data, see Guo and Chen (2009). 
3 One needs to bear in mind that 'urban areas' in FUSSAPUR only include cities and suburbs of the city, but not towns or suburbs of towns, as some other statistics do (e.g. China Statistics Yearbooks).

4 One might argue that this set of dummy variables cannot describe the living distance between the elderly parents and the adult children accurately. Instead of qualitative data (dummy variables in this case), quantitative data should be applied. For example, studies from Europe measured parent-child proximity by travelling distance (e.g. Mulder and van der Meer 2009) or in travelling time (e.g. Grundy, Murphy and Shelton 1999). Unfortunately, our survey does not provide such quantitative information to measure geographic distance. Indeed, the measure this study applied to measure geographic distance was widely adopted by studies in China (e.g. Song and Li 2008; Sun 2002; Xie 2009). We believe our measurement of geographic distance between elderly parents and their adult children is valid for two possible reasons. First, it does offer clear clues as to whether parents are living away from children. Second, our survey collected data from respondents aged 60 and older, who might not know the exact physical distance from their children's households. This is particularly true in rural areas, where elders are more likely to know whether their children live in the same county or live in another county. If this is the case, then our qualitative data suffer from less measurement error than quantitative data.

5 Pre-transfer income could be negative if an individual made a loss from agricultural or other economic activities. The questions regarding rural respondents' incomes of SSAPUR differ slightly from those of FSSAPUR. For this reason, pretransfer income in 2000 was not reported.

6 One might argue that the OLS estimation of the amount of net transfer older parents received suffers from selection bias because older adults may not be randomly assigned but self-select as a net recipient. Some empirical studies on intergenerational monetary transfers (e.g. Lee and Xiao 1998) used the Heckman (1979) two-stage procedure to correct for this kind of selection bias. However, it is difficult to fulfil the exclusion restriction required for this procedure by finding variables affecting the possibility of receiving a positive net transfer, without having an impact on the amount of the net transfers received. This is particularly the case because in this study, whether an older parent was a net recipient or not was calculated from the amount of the net transfers received. A failure to satisfy the exclusion restriction may produce some other problems. Consequently, in this study we have decided to ignore any potential selection bias.

7 Coefficient estimates from transfer amount in models using the Tobit should be interpreted as robustness checks and treated with care. There are two well-established reasons why coefficient estimates from the Tobit model are likely to be biased. First, the Tobit yields inconsistent parameter estimates when errors are heteroskedastic as one typically finds with survey data (Arabmazar and Schmidt 1981). Second, parameter estimates will be inconsistent if the distribution of errors is not normal (Arabmazar and Schmidt 1982) and cursory examination of the skewed distribution of net transfers suggests that this will certainly be the case (not shown).

\section{References}

Aboderin, I. 2004. Modernisation and ageing theory revisited: current explanations of recent developing world and historical western shifts in material family support for older people. Ageing $\mathcal{E}$ Society, 24, 1, 29-50. 
Arabmazar, A. and Schmidt, P. 1981. Further evidence on the robustness of the Tobit estimator to heteroskedasticity. Journal of Econometrics, 1 7, 2, 253-8.

Arabmazar, A. and Schmidt, P. 1982. An investigation of the robustness of the Tobit estimator to non-normality. Econometrica, 5o, 4, 1055-63.

Becker, G. S. 1974. A theory of social interactions. Journal of Political Economy, 82, 6 , 1063-93.

Bengtson, V. L. and Roberts, R. E. 1991. Intergenerational solidarity in aging families: an example of formal theory construction. Journal of Marriage and the Family, 53, 4, 85 6-70.

Benjamin, D., Brandt, L. and Rozelle, S. 2000. Aging, wellbeing, and social security in rural northern China. Population and Development Review, 26, supplement, $89-116$.

Beresford, J. C. and Rivlin, A. M. 1966. Privacy, poverty, and old age. Demography, 3, 1, $247-5^{8 .}$

Boyd, M. 1991. Immigration and living arrangements: elderly women in Canada. International Migration Review, 25, 1, 4-27.

Cai, F., Giles, J. and Meng, X. 2006. How well do children insure parents against low retirement income? An analysis using survey data from urban China. Journal of Public Economics, 9o, 12, 2229-55.

Chen, T. 2014. Pension system in China: an overview. In Harper, S. and Hamblin, K. (eds), International Handbook of Ageing and Public Policy. Edward Elgar, Cheltenham, UK, 318-31.

Cong, Z. and Silverstein, M. 2011 . Intergenerational exchange between parents and migrant and nonmigrant sons in rural China. Journal of Marriage and Family, 73, 1, 93-104.

Dixon, J. E. 1981. The Chinese Welfare System. Praeger, New York.

Folbre, N. 1994. Children as public goods. American Economic Review, 84, 2, 86-9o.

Frankenberg, E., Lillard, L. and Willis, R. J. 2002. Patterns of intergenerational transfers in southeast Asia. Journal of Marriage and Family, 64, 3, 627-41.

Frazier, M. W. 2010. Socialist Insecurity: Pensions and the Politics of Uneven Development in China. Cornell University Press, New York.

Goode, W. J. 1963. World Revolution and Family Patterns. Free Press, New York.

Grundy, E., Murphy, M. and Shelton, N. 1999. Looking beyond the household: intergenerational perspectives on living kin and contacts with kin in Great Britain. Population Trends, 97, Autumn, 19-27.

Guo, M., Aranda, M. and Silverstein, M. 2009. The impact of out-migration on the inter-generational support and psychological wellbeing of older adults in rural China. Ageing Ev Society, 29, 7, $1085^{-104}$.

Guo, P. and Chen, G. (eds) 2009. Data Analysis of the Sampling Follow-up Survey of the Aged Population in Urban/Rural China 20o6. China Social Press, Beijing.

Heckman, J. 1979. Sample selection bias as a specification error. Econometrica, 47, 1, $153^{-61 .}$

House, J. S. 1977. The three faces of social psychology. Sociometry, 4o, 2, 161-77.

Ikels, C. 2004. Filial Piety: Practice and Discourse in Contemporary East Asia. Stanford University Press, Stanford, California.

Jensen, R. T. 2003. Do private transfers 'displace' the benefits of public transfers? Evidence from South Africa. Journal of Public Economics, 88, 1/2, 89-1 12.

Knight, J., Song, L. and Jia, H. 1999. Chinese rural migrants in urban enterprises: three perspectives. Journal of Development Studies, 35, 3, 73-104.

Korinek, K., Zimmer, Z. and Gu, D. 2011 . Transitions in marital status and functional health and patterns of intergenerational coresidence among China's elderly 
population. Journals of Gerontology: Psychological Sciences and Social Sciences, 66B, 2, $260-70$.

Lawton, M. 1977. The impact of the environment on aging and behavior. In Birren, J. and Schaie, K. (eds), Handbook of the Psychology of Aging. Van Nostrand, New York, 276-301.

Lee, Y. and Xiao, Z. 1998. Children's support for elderly parents in urban and rural China: results from a national survey. Journal of Cross-cultural Gerontology, 13, 1, 39-62.

Lei, L. 2013. Sons, daughters, and intergenerational support in China. Chinese Sociological Review, 45, 3, 26-52.

Lei, X., Giles, J., Hu, Y., Park, A., Strauss, J. and Zhao, Y. 201 2. Patterns and correlates of intergenerational non-time transfers: evidence from CHARLS. In James, P. S. and Malay, M. (eds), Aging in Asia: Findings from New and Emerging Data Initiatives. The National Academies Press, Washington DC, 207-28.

Lei, X., Strauss, J., Tian, M. and Zhao, Y. 2011 . Living arrangements of the elderly in China: evidence from CHARLS. RAND Labor and Population Working Paper Series, WR-866. RAND Corporation, Santa Monica, California, USA.

Logan, J. R., Bian, F. and Bian, Y. 1998. Tradition and change in the urban Chinese family: the case of living arrangements. Social Forces, $\mathbf{7 6}, 3,85^{1-82}$.

Meng, X. and Luo, C. 2008. What determines living arrangements of the elderly in urban China? In Gustafsson, B. A., Li, S. and Sicular, T. (eds), Inequality and Public Policy in China. Cambridge University Press, Cambridge, $267-86$.

Michael, R. T., Fuchs, V. R. and Sharon, R. S. 1980. Changes in the propensity to live alone: 1950-1976. Demography, 17, 1, 39-56.

Mulder, C. H. and van der Meer, M.J. 2009. Geographical distances and support from family members. Population, Space and Place, 15, 4, 381-99.

National Bureau of Statistics of China 2012. China Statistical Yearbook 20I 2. China Statistics Press, Beijing.

Palmer, E. and Deng, Q. 2008. What has economic transition meant for the wellbeing of the elderly in China? In Gustafsson, B. A., Li, S. and Sicular, T. (eds), Inequality and Public Policy in China. Cambridge University Press, Cambridge, $182-203$.

Silverstein, M., Cong, Z. and Li, S. 20o6. Intergenerational transfers and living arrangements of older people in rural China: consequences for psychological well-being. Journals of Gerontology: Psychological Sciences and Social Sciences, 61 B, 5, $\mathrm{S}_{25} 5^{6-66 .}$

Song, L. and Li, S. 2008. Sons and daughters: effects of out-migration on division of intergenerational support in rural China. Journal of Xian Jiaotong University, 28, 3, 10-21.

Sun, R. 2002. Old age support in contemporary urban China from both parents' and children's perspectives. Research on Ageing, 24, 3, 337-59.

Waite, L.J. and Hughes, M. E. 1999. At risk on the cusp of old age: living arrangements and functional status among black, white and Hispanic adults. Journals of Gerontology: Psychological Sciences and Social Sciences, 54B, 3, $\mathrm{S}_{13} 6-44$.

Wang, D. 20o6. China's urban and rural old age security system: challenges and options. China $\mathcal{E}$ World Economy, 14, 1, 102-16.

Whyte, M. K. 1997. The fate of filial obligations in urban China. The China Journal, 38, July, $1-31$.

Whyte, M. K. and Xu, Q. 2003. Support for aging parents from daughters versus sons. In Whyte, M. K. (ed.), China's Revolutions and Intergenerational Relations. Center for Chinese Studies, University of Michigan, Ann Arbor, Michigan, 167-96. 
Wu, Z. and Schimmele, C. M. 2008. Living arrangements and psychological disposition of the oldest old population in China. In Zeng, Y., Poston, D. L., Vlosky, D. A. and Gu, D. (eds), Healthy Longevity in China: Demographic, Socioeconomic, and Psychological Dimensions. Springer, Dordrecht, The Netherlands, 397-418.

Xie, G. 2oog. Living arrangement of the elderly and children's caregiving behaviors. Chinese Journal of Sociology, 29, 5, 149-67.

Xie, Y. and Zhu, H. 2009. Do sons or daughters give more money to parents in urban China? Journal of Marriage and Family, 71, 1, 1 74-86.

$\mathrm{Xu}$, Y. 2001. Family support for old people in rural China. Social Policy $\mathcal{E}^{\circ}$ Administration, 35, 3, 307-20.

Yan, S., Chen, J. and Yang, S. 2003. Living arrangements and old-age support. In Whyte, M. K. (ed.), China's Revolutions and Intergenerational Relations. University of Michigan Press, Ann Arbor, Michigan, 143-63.

Zeng, Y. and Wang, Z. 2003. Dynamics of family and elderly living arrangements in China: new lessons learned from the 2000 census. China Review, 3, 2, 95-119.

Zheng, G. and Lu, Q. 2011 . Laoyou suoyang jiqi fazhang lujing [Caring for the aged and its development pathway]. In Zheng, G. and Lu, Q. (eds), The Strategy of Social Security System Reform in China. The People's Publishing House, Bejing, 1-57.

Zimmer, Z. 2005. Health and living arrangement transitions among China's oldestold. Research on Ageing, 27, 5, 526-55.

Zimmer, Z. and Kwong, J. 2003. Family size and support of older adults in urban and rural China: current effects and future implications. Demography, 4o, 1, 23-44.

Accepted I 8 May 20I6; first published online 23 June 2016

Address for correspondence:

Taichang Chen,

School of Public Administration and Policy,

Renmin University of China,

59 Zhongguancun Avenue,

Beijing 10o872, China

E-mail: taichang.chen@gmail.com 